\title{
PHOTOATLAS
}

\section{Opacities in the vitreous}

\section{WDH Gillan*}

Optometric Science Research Group, Department of Optometry, University of Johannesburg, PO Box 524, Auckland Park, 2006 South Africa

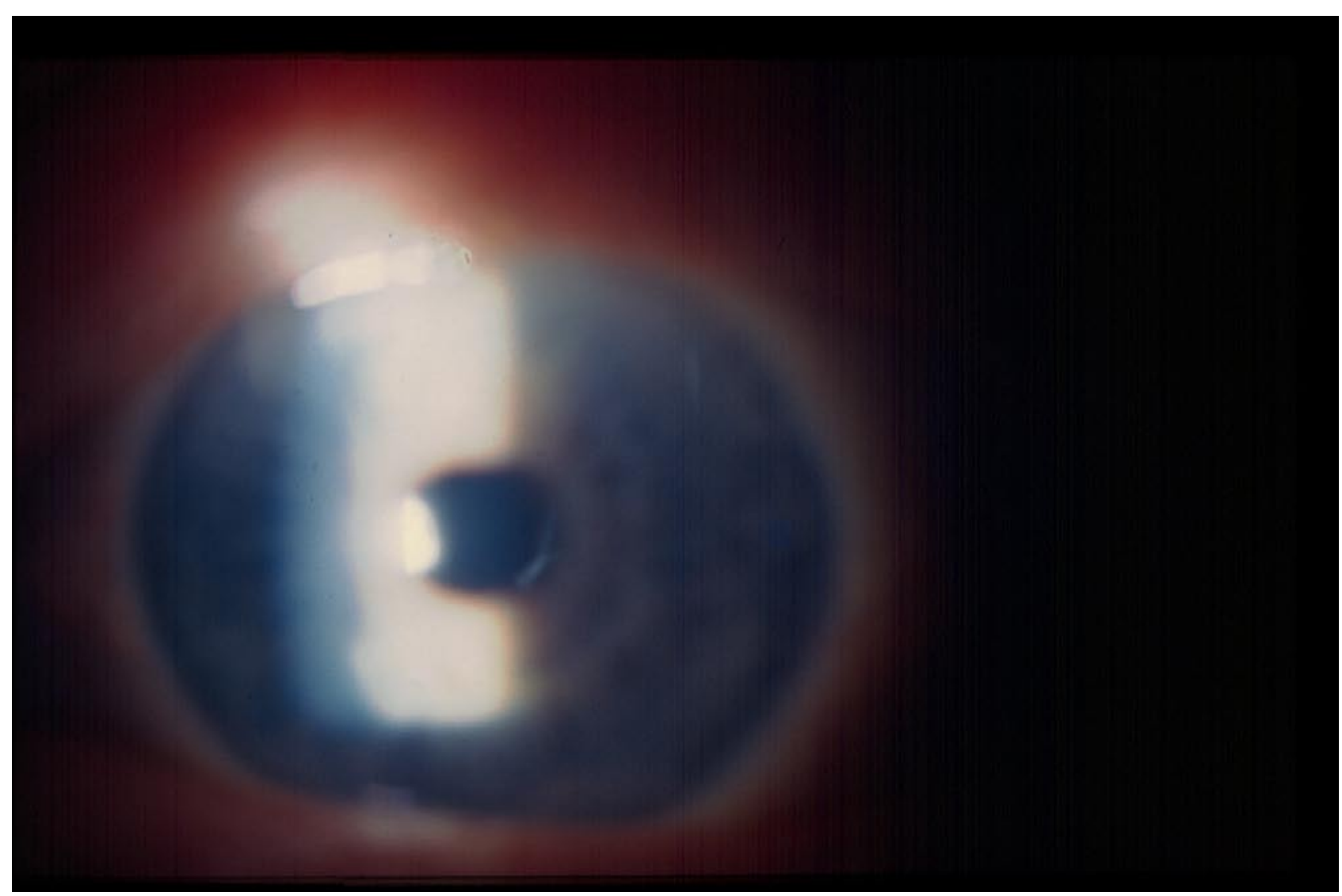

Figure 1

Opacities in the vitreous take various forms. Vitreous floaters (also known as muscae volitantes ${ }^{1}$ ) are usually fine vitreous opacities that, under the correct conditions, can cast a shadow on the retina resulting in the individual being able to perceive what appear to be flitting flies ${ }^{1}$. It is unwise to dismiss the complaint of vitreous floaters as they can be indicative of potentially serious pathology. Some vitreous floaters are easier to see than others. For example, it is usually not difficult to observe vitreous opacities that are a result of asteroid hyalosis or synchysis scintillans ${ }^{1}$.

Vitreous opacities may be due to different primary defects in the vitreous or secondary lesions in the retina and choroid ${ }^{2}$. Roy ${ }^{3}$ lists over twenty causes of vitreous opacities with examples being: amyloid disease, severe myopia, pars planitis, active toxoplasmosis, vitreitis, Wagner's disease. The ability to observe vitreous opacities varies from almost impossible to exceptionally easy. The slit lamp can

*DipOptom MPhil DPhil(RAU) CAS(NewEnCO) FAAO FIACLE 


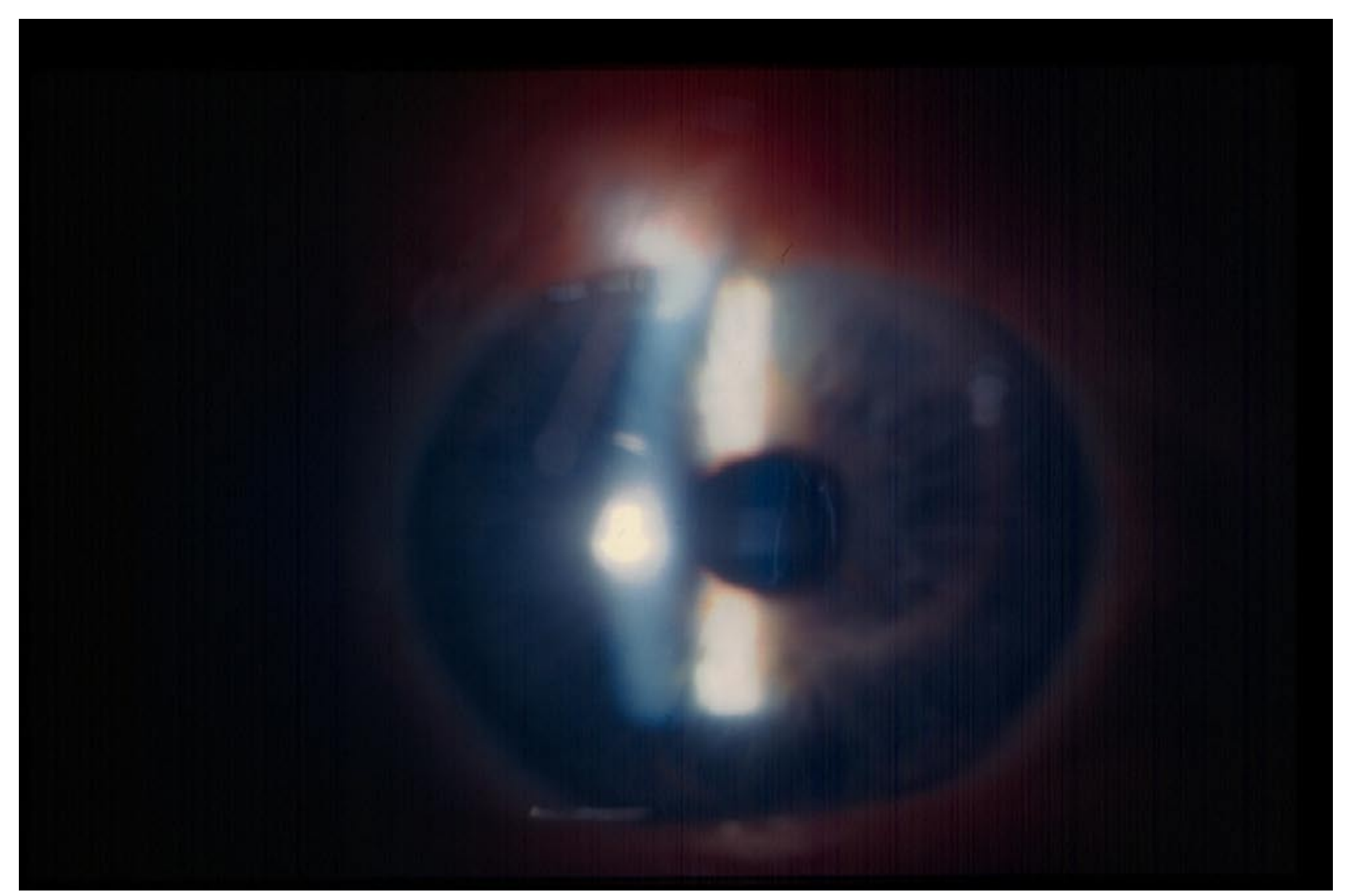

Figure 2

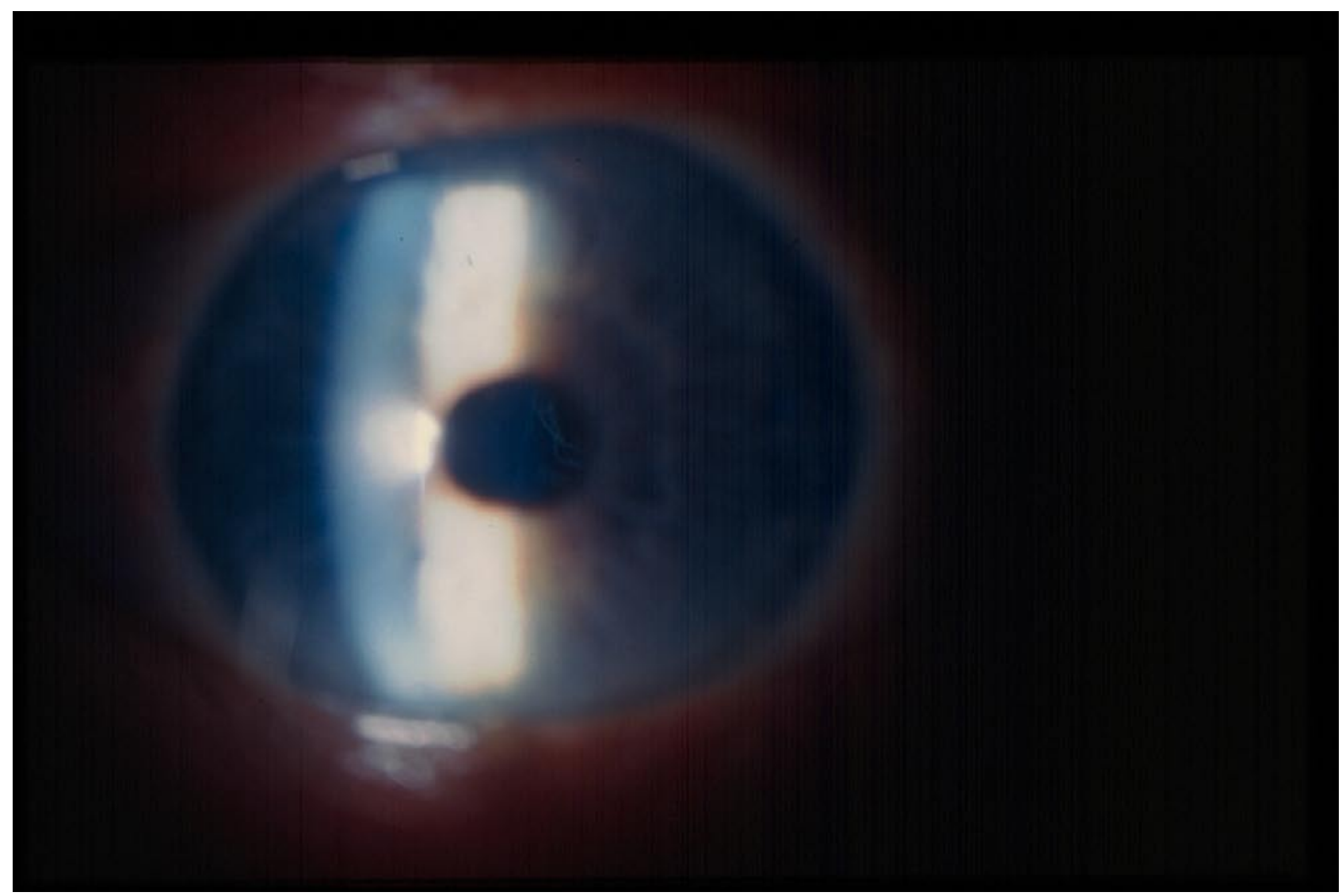

Figure 3 
be used to observe some types of vitreous opacities. In an undilated eye an optic section is focused on the posterior capsule of the crystalline lens (from a reasonably oblique angle). One then attends to the area posterior to the capsule, in the vitreous. If opacities do exist they will be seen as grey or brown (usually) nebulous wisps or strands in the vitreous. The photographs below show these nebulous wisps illuminated by an optic section in a patient who has had vitreous detachment and intraocular lens surgery in the eye.

\section{References}

1. Vaughan D, Asbury T. General ophthalmology. 7th ed. California: Lange Medical Publications, 1974.

2. Trevor-Roper PD. The eye and its disorders. Oxford: Blackwell Scientific Publications, 1974.

3. Roy FH. Ocular differential diagnosis. 6th ed. Baltimore: Williams and Wilkins, 1997. 